\title{
Flood mitigation through riparian detention in response to climate variability - a case study in Taiwan
}

\author{
Kwan Tun Lee $^{1}$ and Pin-Chun Huang ${ }^{2}$ \\ ${ }^{1}$ Center of Excellence for Ocean Engrg., National Taiwan Ocean Univ., Keelung 202, Taiwan \\ ${ }^{2}$ Department of River and Harbor Engrg., National Taiwan Ocean Univ., Keelung 202, Taiwan
}

\begin{abstract}
Considering that urban areas may suffer more substantial losses than riparian farmlands during floods, diverting floodwater into riparian areas for temporal detention is expected to mitigate flood damage in downstream urban areas. In this study, an assessment has been conducted to evaluate the effect of flood mitigation through riparian detention in response to climate variability in the Tou-Chien Basin of Taiwan. A couple 1D-2D model was used to simulate the flood wave transporting in the main stream and the overbank flow inundating into the urban areas. Based on the numerical simulation results, flooding extent and inundated water depth corresponding to different return periods with current flood prevention infrastructures were detailed investigated. Various riparian detention strategies were proposed to alleviate severe losses in the downstream urban areas of the Tou-Chien Basin.
\end{abstract}

\section{Introduction}

Taiwan Island has been evaluated as the most vulnerable region in respect of natural disasters. According to the source, approximately 73 percent of Taiwan residents are threatened by three different types of natural hazards, in which the flood disaster occurs most frequently. As revealed by hourly precipitation data from 21 gauging stations in north Taiwan, the amount of extreme rainfall was found to increase significantly from 1994 to 2011 [1]. Reassessing the criteria of levee height for flood protection is therefore a routine work that cannot be ignored. The design of levee height usually depends on the results of frequency analysis using hydrological records; hence, it can be inferred that the standard of levee height for flood protection would be altered as available hydrological data are extended.

Although levee heightening is one of the most straightforward strategies that can be implemented by authorities, it may not be practically feasible due to a variety of constraints, such as bridge and road reconstruction, land-use planning, landscape considerations, and fiscal budgets. Considering that urban areas may receive more disastrous damage than agricultural areas during floods, diverting part of the floodwater from the main channel to riparian farmlands for flood peak attenuation could be a compromise measure to alleviate downstream urban flooding. The main objective of this paper is to assess the flood mitigation in the downstream urban areas through riparian detention in the Tou-Chien Basin, where the Hsinchu Science Park, referred to as Taiwan's Silicon Valley, is located in the downstream 
of the basin. In the following sections of this paper, climate variability in the basin is firstly investigated through frequency analysis based on available discharge records. Theories adopted in developing the 1D-2D numerical model are described. Spatial distribution of the inundated water depth through numerical simulation corresponding to different return periods are investigated. Various detention strategies through lowering the levees near the predetermined riparian were tested to investigate the flood mitigation in the downstream urban areas. The results is promising to be adopted by authorities to adjust current flood prevention infrastructures along the riparian to alleviate flooding in the urban areas of TouChien Basin.

\section{Study area}

The Tou-Chien watershed is located in northwest Taiwan. The watershed area is about 566 $\mathrm{km}^{2}$ and distributed in Hsinchu County and Hsinchu City. According to the report by the $2^{\text {nd }}$ River Management Office (1998), most of the levees along the Tou-Chien River were built before 1992; hence, the levee-crest design in this basin was implemented according to the frequency analysis using flow record data before 1992. Because more frequent and severe rainstorms have been observed in Taiwan in recent years, a concern was raised about that whether the levee-crest design based on the previous frequency analysis results using early recorded data could meet current flood prevention criterion.

To answer this question, statistical analysis should be employed to realize the variability of the hydrological processes in the Tou-Chien Basin. Five probability distributions, twoparameter lognormal, three-parameter lognormal, Pearson type III, log-Pearson type III, and extreme value type I, were adopted for frequency analysis. The Chi-square test and Kolmogorov-Smirnov test based on a confidence level of $95 \%$ were implemented to examine the acceptability of the probability distribution assumptions. The available records of annual maximum discharge from 1977-2011 were grouped into two segments of data series for analysis. Pearson type III distribution was adopted as a result of the optimal fitness.

Flood peaks derived from the data period of 1977-2011 for different return periods are found larger than those acquired from the data period of 1977-1993 for all the three flow gauging stations in the watershed. Significant increase of the flood peaks for 200-yr return period at Chu-Lin Bridge Station was found from $4223 \mathrm{~m}^{3} / \mathrm{s}$ (based on 1977-1993 data) to $8341 \mathrm{~m}^{3} / \mathrm{s}$ (based on 1977-2011 data). Since the existing levees along the mainstream of TouChien River were built before 1993, the increased flood risk induced by climate variability for the basin can be inferred.

\section{Numerical Modelling}

An integrated numerical model was developed in this study for flooding simulation to realize the flood risk resulting from climate variability and to propose possible strategies for flooding mitigation. In order to execute the hydrological simulations, this study establishes a couple 1D-2D model, which combines a one-dimensional channel flow routing with a twodimensional overland-flow routing. For the channel-flow simulation, a four-point implicit scheme [2] was employed to solve the fully dynamic-wave equation. The diffusion-wave approximation was then applied for the overland-flow simulation because it was proved to provide appropriate simplification for rainfall-runoff routing and accommodate complicated land surfaces $[3,4,5,6]$.

As reported by Cunge et al. [7], overbank-flow calculation can be broadly categorized into two situations based on the flow patterns of submerged or free overflow. The exchange of floodwater between the channel and overland grids, either channel flow inundating to the 
riparian areas or overland flow draining into the channel, can be determined by using following equations:

$$
\begin{aligned}
& Q=C_{1} \sqrt{2 g} \cdot B\left(y_{d s}-y_{w}\right)\left(y_{u s}-y_{d s}\right)^{1 / 2} \\
& Q=C_{2} \sqrt{2 g} \cdot B\left(y_{u s}-y_{w}\right)^{3 / 2}
\end{aligned}
$$

in which $y_{u s}$ is the water surface elevation on the upstream side of the weir; $y_{d s}$ is the water surface elevation on the downstream side of the weir; $B$ is the width of the weir; $y_{w}$ is the weir crest elevation; $C_{1}$ and $C_{2}$ are discharge coefficients. Eq. 1 is used to simulate the overbank flow analogous to a drowned weir; and Eq. 2 is used to simulate the overbank flow in a free-overflow situation.

\section{Model application and discussion}

There are two primary issues planned to be realized in this section via a series of numerical simulations. First is to realize the extent of flooding in the densely populated urban areas induced by the climate variability under the situation of existing levees along the main stream of Tou-Chien River. Second is the performance of the two riparian farmlands to retain floodwater in order to alleviate downstream urban flooding.

To realize the extent of flooding in the densely populated urban areas induced by the climate variability, series numerical tests were conducted under the situation of existing levees along the mainstream of Tou-Chien River. In this study, to avoid using conventional triangular hydrographs, the observed hydrograph at Chu-Ling Bridge for Typhoon Doug was treated as the basic shape to generate design inflow hydrographs. As shown in Figure 1, the peak discharges of the design hydrographs were corresponding to the results obtained from the frequency analysis based on the recorded data from 1977 to 2011 and the shape of the design hydrographs was linearly proportional to the flow hydrograph measured at the ChuLin Bridge during Typhoon Doug.

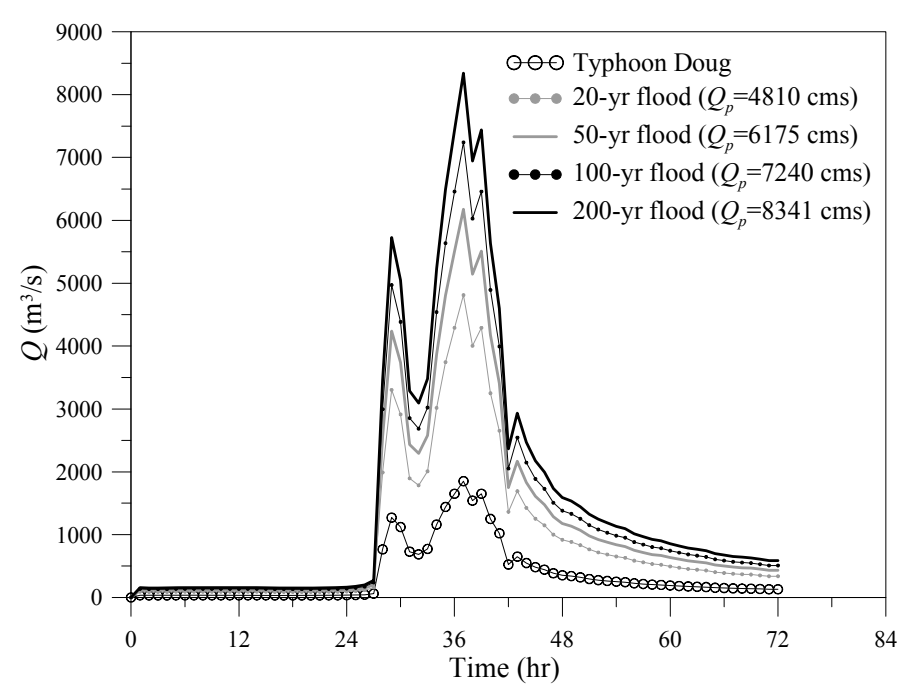

Fig. 1. Designed inflow hydrographs under different return period conditions 
By assigning the existing levee crest and the inflow hydrographs shown in Figure 1, the simulated flooding extents corresponding to 20-yr and 200-yr return-period floods can be seen in Figure 2, in which the inundated water depth larger than $0.5 \mathrm{~m}$ are marked with black. In these figures, the densely populated urban areas are marked out with red lines, and the riparian farmlands for flood detention are marked out with green lines. The results indicate that for a 20-yr flood, a large area of inundation occurs on the left side of the river mouth, where is mainly farmland and recreation parks. Only a small portion of urban area (red line area) on the right side of the river is inundated. However, for a $200-y r$ flood, severe inundation occurs on the entire estuarine area and a large portion of urban area on the right side of the river is also inundated. The downstream inundated region (without counting the flooding area occurred in the riparian farmlands) is $9.6 \mathrm{~km}^{2}$ for the $20-\mathrm{yr}$ flood, and the region reaches to $27.4 \mathrm{~km}^{2}$ corresponding to the 200 -yr flood.

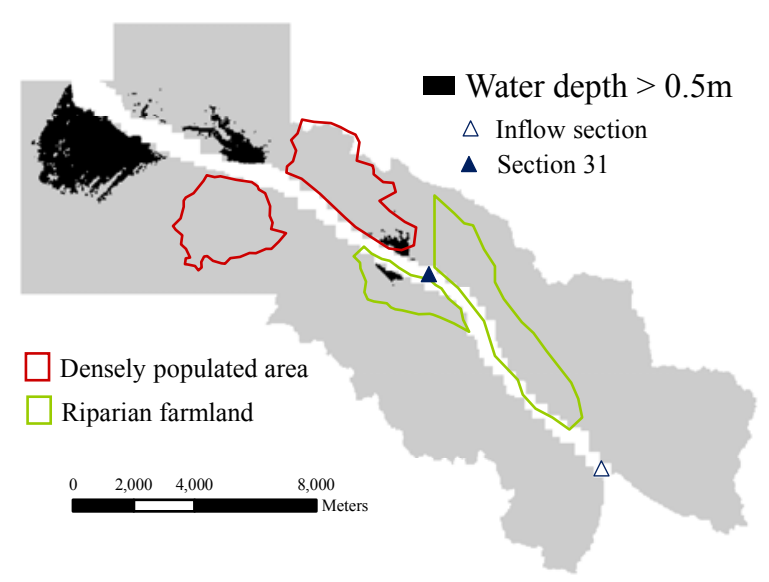

(a) 20-yr return period

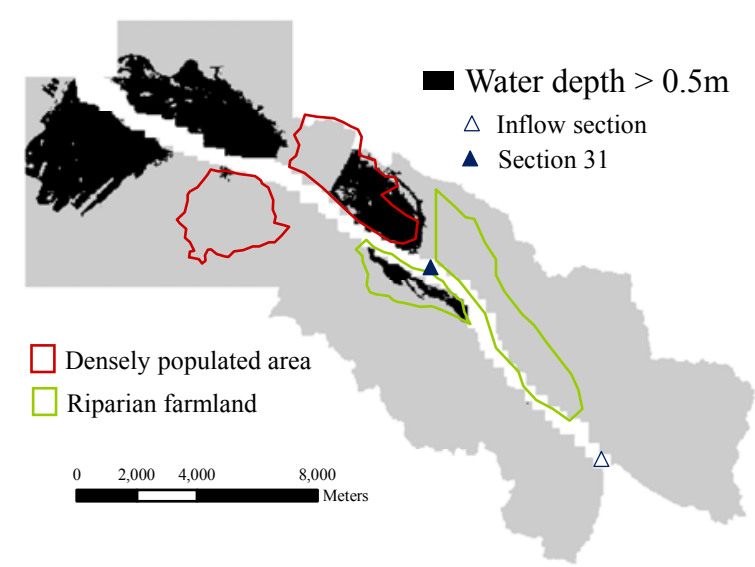

(b) 200-yr return period

Fig. 2. Comparison of flooding areas by assigning inflow hydrographs of different return periods in applying the existing levee height for simulation 
In considering the climate variability to induce more frequently severe floods, heightening levees may be the most straightforward way to prevent severe flooding. However, levee heightening or floodplain extension seems impossible in the Tou-Chien Basin because 14 bridges have been intensively constructed along the downstream channel, and the floodway has been bounded by the densely buildings of the city. Considering the topography and land use conditions in the riparian areas, two farmlands (marked out with green circles as shown in Figure 2) are designated for floodwater detention. Hence, lowering the levee crest along the two farmlands is the main approach in this study to divert excessive floodwater from the main channel to the farmlands for temporal detention. The farmland on the left side of the river is about $5.5 \mathrm{~km}^{2}$; and the other one on the right side of the river is $12.9 \mathrm{~km}^{2}$.

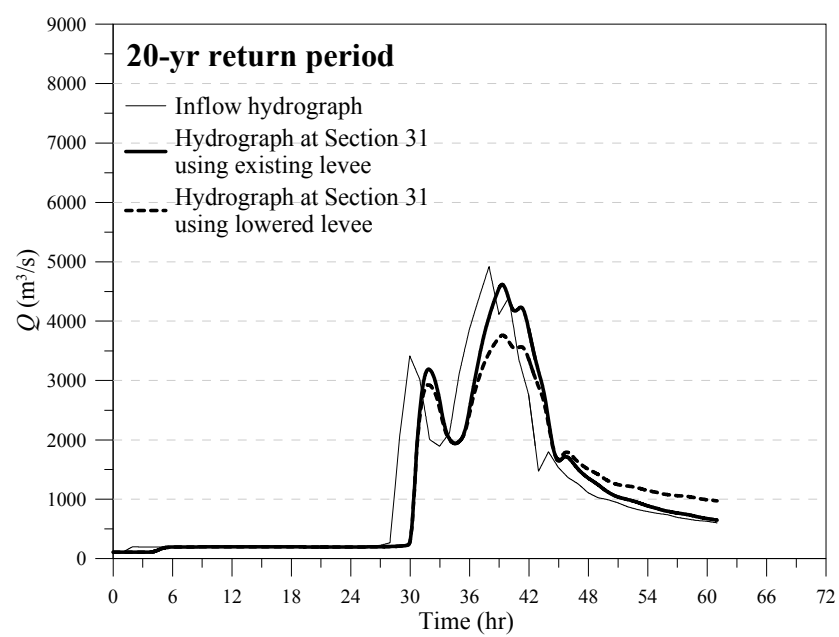

(a) 20-yr return period

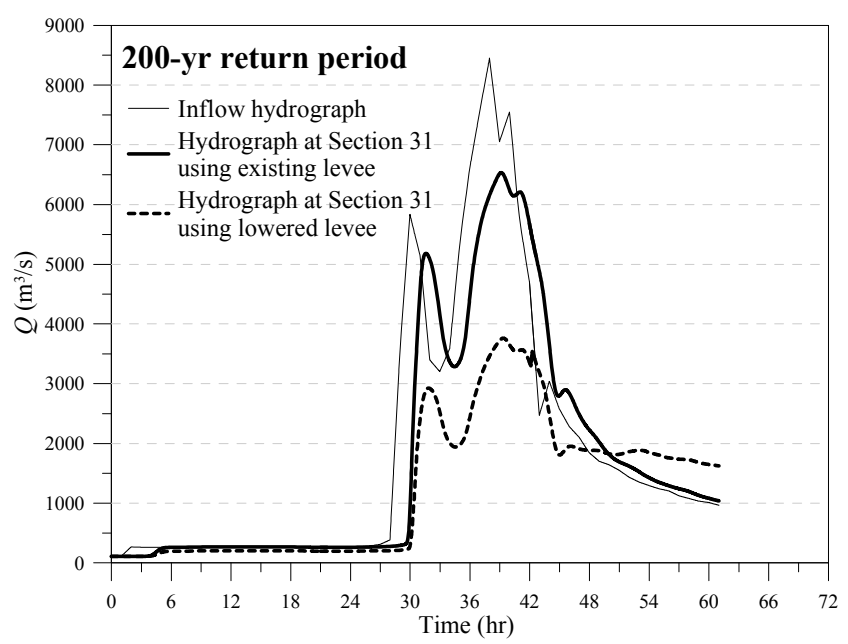

(b) 200-yr return period

Fig. 3. Flow hydrograph analysis at Section 31 for the existing levee crest and lowered levee crest cases 
To investigate the influences of two designated farmlands on flood peak attenuation, numerical simulations were performed using the existing levee crest and the levee with lowered crest. Since Section 31 is located at the downstream end of the farmland on the right side of the river (as shown in Figure 2a), it would be easy to investigate the flood peak attenuation resulting from the detention of the farmlands through examining the hydrographs. Figure 3 shows the upstream inflow hydrograph for the channel-flow routing as well as the simulated hydrographs at Section 31 based on different levee height scenarios. The solidbold line is the hydrograph generated by using the existing levee crest as model input condition, and the hydrograph shown by bold-dashed line represents the scenario using the lowered levee in the modeling. Lower peak discharge and delayed peak time can be found in the simulation using the lowered-levee scenario. The flood peak at Section 31 is attenuated from $4665 \mathrm{~m}^{3} / \mathrm{s}$ to $3792 \mathrm{~m}^{3} / \mathrm{s}$ for the 20 -yr flood due to the flood detention within the farmlands, and the peak discharge is significantly diminished from $6534 \mathrm{~m}^{3} / \mathrm{s}$ to $3762 \mathrm{~m}^{3} / \mathrm{s}$ for the 200-yr flood.

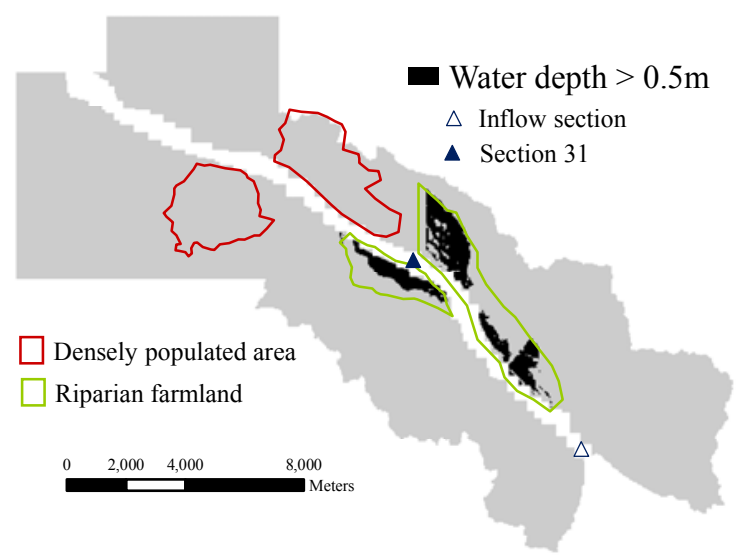

(a) 20-yr return period

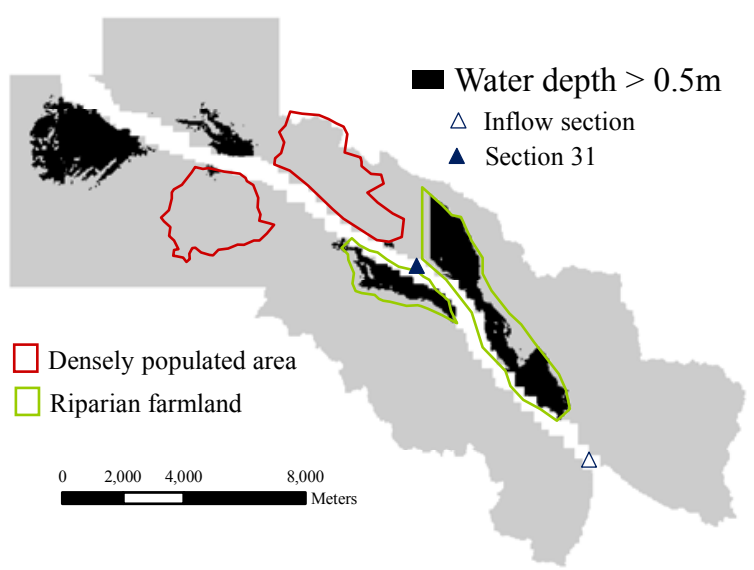

(b) 200-yr return period

Fig. 4. Comparison of flooding areas by assigning inflow hydrographs of different return periods in applying the flood detention measure for simulation 
Figure 4 shows the spatial distribution of flooding areas in applying the lowered levee along the farmlands for simulating under different return-period floods. The results indicate that the proposed flood detention measure can only prevent overbank flooding in the downstream areas for a storm lesser than a 20 -yr return period. For a flood larger than 20 -yr return period, inundation mainly occurs on the left side near the river mouth, where is mainly farmlands and recreation parks. Nevertheless, the flood risk can be completely prevented in the densely populated urban areas (the red-line areas) even for a flood reaching up to 200 -yr return period.

\section{Summary}

As climate variability has intensified flood hazards in Taiwan during recent years, proposing feasible plans for flood mitigation is required. According to the result of trend analysis, the flow records collected from Tou-Chien Basin shows an increasing tendency in the period of 1994-2011. For this reason, the efficacy of the existing levees, which were built before 1993, need to be reevaluated. The 1D-2D simulation results indicated that the existing levees cannot prevent the flooding in the densely populated urban areas for a flood event higher than 20 -yr return period. Therefore, diverting floodwater to upstream riparian farmlands was proposed in this study by taking advantage of the inherent topographic conditions of the basin. A series of numerical simulations showed that the flood detention measure is capable of inhibiting downstream overbank flooding for a 20 -yr flood and effectively reducing downstream flooding area from $27.4 \mathrm{~km}^{2}$ to $7.6 \mathrm{~km}^{2}$ for a 200 -yr flood. Although the downstream flooding cannot be completely relieved when the proposed strategy was implemented, flood inundation would occur in the downstream paddy fields or recreation parks instead of the densely populated urban areas.

\section{References}

1. S.-H. Su, H.-C. Kuo, L.-H. Hsu, Y.-T. Yang, J. Meteorological Society of Japan, 90(5), 721-736 (2012).

2. A. Preissmann, First Congress of French Association for Computation 433-442 (1961).

3. V. M. Ponce, R.-M. Li, D. B. Simons, J. Hydrau. Div. 104, 353-360 (1978).

4. M. Wang, A. T. Hjelmfet, DEM based overland flow routing model. Journal of Hydrologic Engineering, ASCE 3:1-8 (1998).

5. M. K. Jain, V. P. Singh, DEM-based modeling of surface runoff using diffusion wave equation. Journal of Hydrology 302:107-126 (2005).

6. D. Pantelakis, T. Zissis, E. Anastasiadou-Partheniou, E. Baltas, Numerical models for the simulation of overland flow in fields within surface irrigation systems. Water Resour. Manage, 26:1217-1229 (2012).

7. J. A. Cunge, F. M. Holly, A. Verwey, Practical Aspects of Computational River Hydraulics. Pitman Publishing Ltd., London (1980). 